\title{
Ethnographic Stories as Generalizations that Intervene
}

\author{
Brit Ross Winthereik and Helen Verran
}

\begin{abstract}
Located within classic and more recent works in STS the paper grapples with the question of how to write ethnographic stories that generalize particular spacetime places, and simultaneously generalize about their own modes of existence. Growing as a prolonged, cross-generational, and transcontinental conversation between the two authors the paper discusses the capacities of ethnographic stories to work as generative interventions. We begin with the situation in which most ethnographers of science and technology find themselves: navigating a passage in projects in which ethnographic analyses are obliged to work instrumentally in relation to organizational or technological change. Developing with an ethnographic description of monitoring work in an environmental NGO and Latour's analysis of a Holbein painting, we draw on Strathern's notion of partiality and Haraway's articulation of double vision.
\end{abstract}

Keywords: ethnography, generalization, partiality

\section{Introduction}

In this paper we discuss how analysts of social and cultural phenomena might think about the epistemic and aesthetic work embedded in the crafting of ethnographic stories. Our point of departure is the observation that when the micromechanics of crafting ethnographic stories is discussed in Science and Technology Studies (STS), it is often done to either to point to the complexity and multiplicity of this endeavour (Law, 2004) or as a move with which to protect STS and its analytical enterprise from influential, yet naïve, ideas about the usefulness and relevance of social science (Zuiderent \& Bruun: \& Bruun Jensen, 2007). Whereas we sympathize with this existing work, we propose that ethnographers of science and technology also attend to specifying the multiple ways in which their ethnographic stories are agential. If ethnographic stories make and work relations, how might we become better equipped for making them participate in building the common world (Stengers, 2005; Latour, 2010)?

Our starting point is to recognize that ethnographic stories have in them a capacity to re-present the world in ways that are generative for the people and practices that the stories are about, as well as for the authors and their academic collectives. This is increasingly important in a situation where the distance between ethnography as a set of methods for knowing about social relations, on the one hand, and what might be termed cultural- 
analytical scholarship, on the other, has increased. We wish to highlight the power of ethnographic analysis and storytelling when working as ethnographers of science and technology in multi-stakeholder situations. As we will show, recognizing this duality is a first step towards also seeing the broadness of the interventionist potential of our ethnographic stories. Thus, the contribution of our paper is a theoretical one. It lies in providing and provoking a discussion of how ethnographers of science and technology might be more attentive to ethnographic stories as instruments that make intervention possible. On the one hand, our ambition is thus to participate in the long-standing debate in anthropology and STS of how to represent worldly phenomena adequately (e.g. Clifford \& Marcus, 1986; Daston, 1992). On the other hand, we recognize the specific historicity of ethnographic stories as a knowledge product in contemporary STS (Lave, Mirowski \& Randalls, 2010). Our attempt can be seen as embedding a shift from a postmodern concern about the authority of the author to a concern about partiality and generative critique.

A central question is: How to re-present others and their diverse practices in good faith? The question may seem like a moral one and it is, too. Yet the anti-thesis to good faith analysis is not bad faith analysis, because this would assume a moral high ground that we have no reason to argue in favour of. Instead, what we would indeed like to point to by this term is that in a multistakeholder situation where participation and engagement in one's field of research is presupposed and generally perceived to be a good thing, alerting oneself to good faith is alerting oneself to the possibility of a double-vision. Good faith is about seeing the possibility of writing generalizing ethnographic stories that intervene, not despite, but because of the partiality of research and analysis. Our attention to a partial perspective is a way of working around the dualism embedded in the opposition between a traditional academic perspective, which is often considered non-interventionist, and engaged research, which is often considered interventionist and therefore good in some general sense. In contrast, good faith analysis is about having faith in it being possible to write stories that are generative for some of the practices we study and for some of our own colleagues in social theory.

In what follows, we argue that ethnographic stories have the capacity for at least two moments of generalizing: A onemany form that enables abstracting, and a whole-parts generalization that brings with it a situating moment. Haraway alerts us such double vision in her cyborg manifesto.

\section{From one perspective, a cyborg world is about... the final abstraction... a Star Wars apocalypse. From another per- spective [it] might be about lived social and bodily realities... The political struggle is to see from both perspec- tives at once because each reveals both dominations and possibilities unimagi- nable from the other vantage point. Sin- gle vision produces worse illusions than double vision or many-headed mon- sters. (Haraway, 1991: 154)}

In her work Haraway highlights the possibility of writing stories which present one reading of the empirical and acknowledge that other stories could have been possible. This insight is fruitful for ethnographers working in STS whose research is already and always embedded in multi-stakeholder situations. This should not lead to STS-researchers striving for writing stories that satisfy collaborators and stakeholders in the sense that they narrate what collaborators hope to hear. Rather, we 
want to argue in favor of stories that point out both the single vision and the many-headed monsters in socio-technical practices. Both single visions and many-headed monsters must be dealt with through careful representation.

Our interest in ethnographic stories is also in part inspired by Latour's compositionist manifesto, where following Stengers, he urges a careful slowing down (Latour, 2010). We want to show just what is involved in doing that. We see ethnographic stories as offering commentary on the everyday and while recognizing that this is not a new formulation (Baumann, 1990: 214; Rouse, 1993: 57), we insist that offering commentary should be understood as a form of diving into the everyday. Fieldwork, but certainly also writing is a way of doing this. Thus, writing it is not a way of resigning from where the action is, but allows us to be dealing technological cultures and futures in-the-making long after field work has been terminated. Inventing the field by repeatedly making it available (Winthereik et al., 2002) is an infra-move designed to show what the everyday is made of. We claim that such a commentary has its agency enhanced by constituting in it an irresolvable tension. In pushing readers to actively engage with an ethnographic text through incorporating a disconcerting moment, the text itself works on the everyday as a loosening agent, rather like the proprietary mix one might spray on a rusted hinge. The proposition such an ethnographic story puts forward should be felt as a an attempt at "paving the way along which the world advances into novelty" (Whitehead, 1929/1978: 187), or more modestly as a hope is that such commentary might at least help to prevent further hardening of the categories of the everyday.

\section{Ethnographic Stories as Generalizations}

...in which we introduce generalizations as performative, as ways of making and negotiating different realities.

Ethnographic stories get their interventionist potential if it is recognized that a particular tension might be incorporated into ethnographic stories. Through a notion of adequate stories Christine Hine points out how ethnographic stories often speak to heterogeneous audiences. Adequate stories are agential in the sense that they "have the capacity to surprise, challenge, or offer new conceptualizations" (Hine, 2007: 668). In her view the crafting of a field site is always done with an eye to how the research may potentially intervene.

Multi-sited ethnographers craft field
sites with an eye to producing appropri-
ate accounts for heterogeneous audi-
ences comprising diverse sets of peers,
policy makers, funders, bosses and
research contacts. Rather than pre-
existing theory in the middle, there is
instead an embodiment of tensions, in
the ethnographer attempting to sustain
a sense of meaning in the project out of
diverse responses and accountabilities.
(Hine, 2007: 657)

Hine's adequate stories point to audiences ("find" them). While this is one aspect of the performativity of ethnographic stories, we want to highlight the capacity of ethnographic stories to also point for them, i.e. invite them to do work to see their own ontological commitments.

Perhaps the first thing to recognise about ethnographic stories, therefore, is that they are (re-)performances, re-presentations of some here-now. Crapanzano (1992) is the classic text in anthropology 
developing the insight that ethnographic descriptions are storytelling events. This is controversial for beginners who, trying their hand at ethnography for the first time, often worry about ethnography as storytelling, voicing their concerns over the subjectivity of their ethnographic data. Acknowledging this we suggest ethnographers commit to a realism of the sort that Ian Hacking develops in his book Representing and Intervening (Hacking, 1983). Hacking insists that we recognise the collective enactment of knowledge practices in devising representations, or more to the point, re-presentations. It is not that reality gives rise to representations, but rather that

[o]nce there is a practice of representing, a second order concept follows in train. This is the concept of reality, a concept that has content only when there are first order representations.

It will be protested that reality or the world, was there before any representation or human language. Of course. But conceptualizing it as reality is secondary. First there is this human thing, the making of representations. Then there was the judging of representations as real or unreal, true or false, faithful or unfaithful, then there comes the world not first, but second, third, or fourth. (Hacking, 1983: 136)

As a (re-)performance, an ethnographic story is first and foremost making reality. "First there is this human thing, the making of representations" (Hacking, 1983: 136). As a re-presentation, the ethnographic story works indexically with an infinitely complex here-now. It is a text that points to a herenow ("the world"). Ethnographic stories re-present, just like the list of contents at the front of a book, or the alphabetic index at its end; they are inherently performative, offering some sort of a guide to somewhere or something else that is infinitely more complex. Indexicality depends on positing a somewhere or something else that is real in a different manner (Verran, 2011). In being indexically implicated in a here-now, an ethnographic story can be described as a generalisation. As a unified text, a narrative, it exemplifies and enacts a particular time and place (condensing it as a here-now). As indexes they foreground, background, and render some things out of the frame. Or to use the terms of John Law, ethnography, as what he calls a method assemblage is

the enactment of presence, manifest absence, and absence as Otherness....the crafting or bundling of relations... (Law, 2004: 84)

Thus, a corollary of seeing the ethnographic story as an index is that there are many, many differing sorts of indexes that could be created. An important part of understanding how ethnographic stories are generalisations, then, is recognising how they deal with necessarily being just one of infinitely many possible stories of a herenow.

Attending to the ethnographic story implies attending to indexes, for here-nows that embed two logics of generalization (one-many and whole-part generalization). One kind of story embeds a logic of generalization (one-many) that re-presents its here-now as an example of something in general. Following this logic we may think of the ethnographic story as an example in a collection of stories adding up to form the 'evidence base' of a general statement about human behaviour, the world etc. Another kind of story embeds a logic of generalization (whole-part) that re-presents its here-how by first building this world. Following this logic we may 
think of the ethnographic story as an emergent entity in a vague whole, whose parts will never add up to a complete picture. There are then two main sorts of ethnographic stories indexing here-nows. Depending on how one renders a here-now - as a collection of entities adding up to a coherent or unified many, or as a vague whole with emergent parts - the logic of generalisation will alter to adopt a onemany form, or a whole-parts form. ${ }^{1}$

We are specifically pointing to the generalising possibilities of ethnographic stories here, but the contrast we are making between forms of reasoning in generalising is not new. Chunglin Kwa points to a similar duality in the twentieth century history of complexity theory (Kwa, 2002: 23). He glosses the distinction we make between one-many generalising and whole-parts generalising as a contrast between the Romantic and the Baroque, and shows us how they featured in the ways theorists dealt with complexity in the twentieth century. He notes for example, that some identify the philosopher Alfred North Whitehead as a Romantic while others claim him as a neobaroque philosopher. John Law (2004), who is interested in the duality of how social sciences have traditionally 'done' complexity, has picked up on the Kwa duality of the Romantic and the Baroque and made a similar exhibition of these dual ways of doing complexity. He invites us to choose between them as paradigms of complexity. In contrast to Law, we suggest that both forms of generalisation are needed, and should sometimes be wittingly used simultaneously.

In order to better imagine what this might involve with regard to writing ethnographic stories in our next section we mobilize Latour's analysis of a $16^{\text {th }}$ century Dutch painting where two men of the world are portrayed. The painting vividly pictures their activities: Making one-many abstracting generalizations through use of a range of instruments as carefully drawn as the men themselves, yet simultaneously situating these activities as mere part of the vague whole that is a human life. Subsequently, using Latour's exemplification of the two moments of generalizing as an analogy we present a field note and discuss how this note might fulfil the criteria we discussed for a good ethnographic story. Using this material we show STS ethnographers how to wittingly engage the capacity for movement between the different generalizing logics. This is the interventionist potential of generalizing ethnographic descriptions that Haraway alerted us to by pointing to the double vision of the cyborg manifesto.

\section{“The Ambassadors" (1533)}

... in which we introduce a paper published some ten years ago by Bruno Latour, where he treats us to a reading of Hans Holbein's The Ambassadors (1533) under the title "a crucial difference between instruments and angels"(Latour, 2001: 9).

Just as the painting, rendered by the particular skills of its craftsperson, is composed so as to invite the viewer to engage with it through movement, an ethnographic story that incorporates the distinct logics of generalizing also moves its reader. Let us explain how this might happen by first looking at the painting and Latour's rendering of it. 


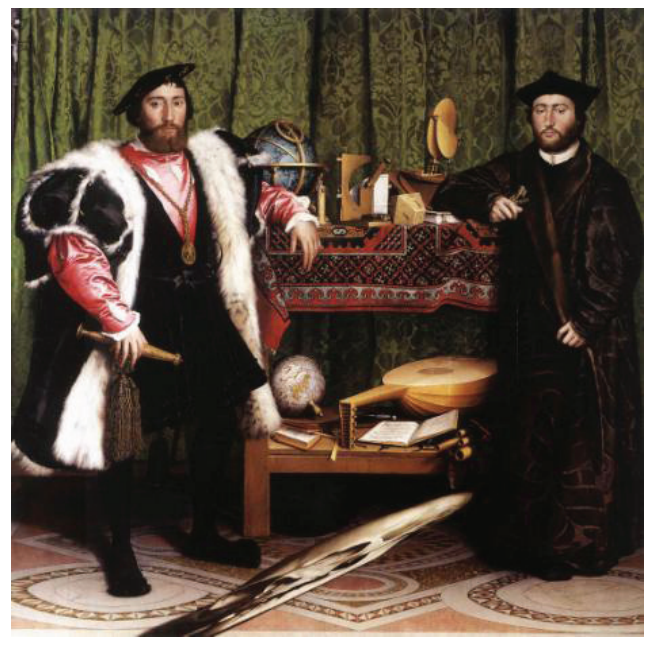

Figure 1. The Ambassadors (1533) Hans Holbein the Younger in the National Gallery, London.

Two men stand full of themselves, types of the Reformation and early European colonizing. They are ambassadors, they carry messages, and in this picture they are rendered in a perfect geometrically constructed space. "They represent the world, men, merchants, and the sciences. They have become instruments, recording devices" (Latour, 2001: 12.) But what of that peculiar brownish object, shaped like the backbone of a cuttlefish that seems to disfigure the lower section of the painting? Clearly it is in the painting, but not an object in the scene so calculatingly depicted.

Let us lean over the edge of the painting... The cuttlebone becomes a skull [a reference to vanity, a memento mori]. But what happens, now, to the proud ambassadors? They turn into deformed monstrous bodies... One cannot hold at the same time, and in the same relation, representation [constancy] and representation [transformation]. (Latour, 2001: 10)

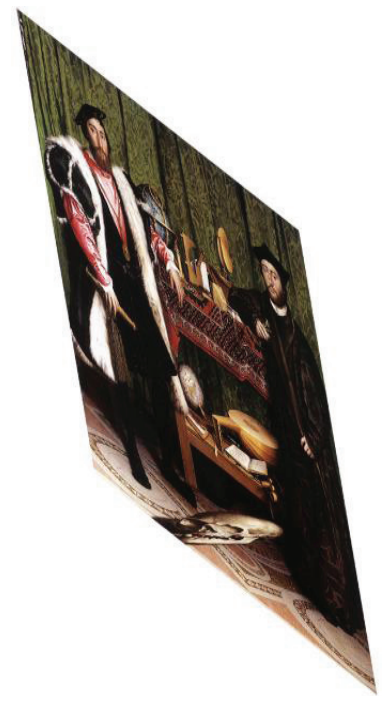

Figure 2. Leaning over The Ambassadors (1533) Hans Holbein the Younger in the National Gallery, London, seeing the skull.

A delicate holography lies at the translational core of this painting, a holography achieved through the technique of anamorphosis that invites the spectator to shift her perspective. When seeing the ambassadors and their instruments in their full glory the skull is only visible as an amorphous object, a cuttlebone. In order to see the disfiguring object as a skull, and take in another meaning, the spectator needs to move her body.

Amongst the objects depicted in the painting is an interrupter, which means that the painting incorporates a challenge to all who wants turn it to their own purposes. It is agential and carries with it an instrumentality that might have been negotiated between Holbein and the Ambassadors as the painting was made and which must also be negotiated by the audience who must lean over to capture the different moments evoked by the painting. 


\section{Illustrations}

... in which we present an illustration of an ethnographic story that mimics the ways Holbein's painting works. We also introduce a field note, composed for the purpose of the present paper as a way of backtracking the process of how we might begin going about writing ethnographic stories embedding the dual logic.

An example of how the Holbein painting may inspire the writing of ethnographic stories is embedded in the story of the remaking of value through 'doing length'. Involved in this is Mr. Ojo (a teacher), a few Nigerian classrooms, children, and low-cost measuring devices (Verran, 2001). In her capacity as a teacher of Yoruba teachers, Helen Verran observes differences in 'doing length' and in valuing. In her story new objects are generated along with new sorts of knowers. Neither and both are Yoruba and neither and both are scientific; measuring in this case turns out to be a many-headed monster. Folded into this story is also an ethnographer, a knower alert to these new sorts of objects and subjects. This is not a 'second order knower', but a subject of infra-ontological work; a figure that sits alongside and engages with those new sorts of numbers and their knowers in the classroom and in the text. Annemarie Mol's re-telling of Verran's text emphasizes how the ethnographer is produced through a kind of self-exposure in the text that allows the analysis to change track, tell different stories or articulate different objects.

Verran relates her ethnographic moment as one where everybody laughed. The teachers had all been sent out to teach their pupils to measure length. The schools were underfunded, so pupils were to measure each child with a cheap piece of rope, and then compare this rope with the single available yardstick: a wooden meter rule lying on the floor. One of the teachers, however, Mr. Ojo, reported that he had worked in a different way: he had taught his pupils to make cards ten centimeters across, and then roll their ropes around these. If you can roll your rope seven times round your card, your length is $1.40 \mathrm{~m}$. This was wrong: rolling is quite unlike adding centimeters together, stretching them out. But no, it was Yoruba as it involved folding up units of twenty. And it brought out a tension: everyone present belly laughed when they heard the story. (Mol, 2011: 114)

The story of Mr. Ojo, as it is told in Science and an African Logic (Verran, 2001) intervenes in two scientific paradigms: Universalism and relativism and thus in any kind of 'foundationist thinking. It does so by telling about how Mr. Ojo has found an alternative mode of measuring length. This measurement questions epistemology and truth in universalist and relativist accounts. The story tells about the dual logics of generalizing in valuing and measurement by 'nodding' acceptingly to the two paradigms. The story thus recognizes and accepts that the world is always seen from somewhere in particular, and this particular somewhere may be a place that claims to be seeing 'a whole' in some form or the other (universalism, relativism). Yet, after the accepting nod, the story goes on describing the embodied efforts to answer a set of questions than universalism and relativism cannot provide answers to. The story describes the ethnographer's work of finding out what the question is, if the tencentimetre cards provide the answer. This struggle to index the world so as to turn length into something other than what we thought it was is one interventionist move 
as it reminds us of both Western and Yoruba length as partial. And even if the story is in some sense amusing, and provokes laughter in the situation, the laughter establishes a disconcerting moment (Verran, 1999) and reminds readers of the constant work of figuring out just what the world is made of.

In the environmental NGO, where one of the authors carried out fieldwork in 2010-11, she meets June, who is heading one of the development programmes, and also a single mother. ${ }^{2}$ June has many things to be worried about and this becomes the topic of a conversation between her and the ethnographer one Tuesday morning in the office. She is worried about having to stay at home to take care of her children, about her troublesome ex, about not being able to visit and monitor her projects as often as her male colleagues do. She is also worried that the technical progress reports that her partners use to account for how things are progressing at the projects are not satisfactorily filled in; and she is worried that the reports filled in by autonomous partners and uploaded in the organization's common database will be interpreted by her colleagues as an expression of incompetence on her part.

One of the tasks associated with running multiple projects together with partners in developing countries as June does is to make sure these partners account for how a project is progressing. To do so partners must submit a progress report every sixth months. These reports are used for accountability purposes internally in the NGO. In conversation with the fieldworker, June puts emphasis on how the reports are both a means for the partners' selfreflection on the progress of the project, and some kind of information repository vis-à-vis the state agency, which finances the NGO's environmental work in developing countries. For monitoring processes to work satisfactorily, June always requests that her partners give her the opportunity to comment on drafts of the progress reports before they are uploaded to the database, where the progress of all the NGO's international projects can be viewed. This procedure of viewing a draft of the reports before they are uploaded to the database enables her to strengthen the quality of their account in relation to overall principles and strategies of the NGO. It also makes her own reporting work vis-àvis external accountants and the ministerial state agency easier, since commenting on the partners' progress report allows her to adjust formulations so that they fit into the categories in the annual report to the funding state agency. Commenting on drafts enable her to stay in contact with her partners and ensures - perhaps - that some kind of accountability chain can be established between the local project partners and the state agency. But sometimes the chain is broken. An example of this, June explained, took place when one of her project partners decided to send their progress report directly to the international office of the environmental NGO, not passing it by June's mailbox and critical review first. The international office runs and maintains a database with information on all the ongoing and closed projects of the network, and this was where the progress report ended up, without comments from June.

"Look, this is an example of a report that I was not given a chance to comment on". June hands over a print of the technical progress report, which has her handwriting in the margins. After having made the hand-written comments she discovered that the partner had uploaded the document to the central database at the same time as it was sent to June. June points to three places where she would have liked to influence the final result. First, her partners have not made any difference between 
indicators and outcome in the report. This is a major mistake, June says. As it stands, indicators and outcome are almost completely identical, but in fact, indicators and outcomes are very different types of categories: "describing an outcome is about describing a change in behaviour, and they haven't done that. They have only repeated what the indicators were: 10 district schools implemented environmental education is an indicator, it is not an outcome; outcomes should tell about changes in behaviour". Another issue that June would have liked to adjust is that in the progress report it is also stated that the project period has already been extended one year. It is likely, June explains, that this extension will be granted, but it has not happened yet and thus it should not appear in the progress report. June would have preferred to influence the final formulation in relation to this specific point, as well as the overall self-evaluation. The self-evaluation is the third and for our purposes most critical/interesting point.

In the progress report partners are requested to rate their own performance on a number of conclusive points from 'low' to 'excellent'. In this case, the result of the self-evaluation in this specific case is 'modest' on four out of six points. June is wondering about this. "Putting 'modest' in so many cases is strange as the progress in this project is actually quite good. Why have they done that?" She makes sense of this low self-evaluative ranking with reference to the project worker, whom she thinks has made the evaluation. June knows this worker. She is a woman, and therefore, in June's understanding would almost certainly underestimate her own performance. June emphasizes how she would really have liked to influence the project worker's self-evaluation before the report was uploaded to the database kept by the international office.
Partly in response to June's worrying the ethnographer shows an interest in browsing the central database and together they log in. The project they have just discussed is easy to find by means of the project ID. They look at the project document and realize that all the cases of 'modest' have magically been changed to 'good'. June is really, really surprised. One of the reasons she is surprised is that usually the Head Office database is totally ignored by project workers. They use it for uploading information, but nothing is retrieved apart from contact information of colleagues in their network. But an ethnographer with a vested interest in following information technologies and how they participate in chains of global accountability is interested in the database, albeit for quite different reasons than anyone else in the office might be.

\section{Double Vision and Recognizing a Disfiguring Object in the Field Note}

\begin{abstract}
...in which we explore the double vision further and establish a possible link between the ethnographic story that might be developed from this field note and Latour's reading of the Holbein painting.
\end{abstract}

What might be made of this field note? Here are some possibilities: A project worker whose gendered insecurities might or might not lead to an interesting generalization about ways of knowing development projects; a database that works 'magically' and which, through the presence of the ethnographer, gains a prominence it usually does not have; and indicators that have yet to come to life in the collective of the Zambian partners in the project. How to turn the note into an ethnographic story, which re-presents both the specific time and place of a Tuesday morning in a Copenhagen office including descriptions 
of project work insecurities and concerns and monitoring in a world of inaccurate yet trusted databases and not yet accomplished indicators?

As a one-many generalization, the incidents around the database, the gendered insecurities of the project worker, and accomplishing working indicators is one of many possible stories about monitoring in general. Seen from this 'angle' the episode will be told as about a progress report and a database as tools in a global attempt to monitor development partners in remote (African) project sites and elsewhere. June and her colleagues use these tools to live up to international standards for good monitoring and effective partnerships in development aid. They may not be entirely successful, but they trust in the tools as a way of supporting communication with partners and trust it as a tool that helps the organization achieve further funding by being able to document aid activities. The story will exemplify the socio-materiality and the hard work of building and maintaining transparent practices in aid partnerships. Thus, 'June and the Database' could become a specific exemplification of technologically mediated monitoring work, comparable to other exemplifications of monitoring.

Alternatively, we may consider the reports, June, the database, and the fieldworker as participants in an assemblage where all actors are somehow emerging parts. Using this approach, one accepts that one does not yet know what monitoring is or may become, monitoring remains a vague whole consisting potentially of multiple presences and manifest absences (cf. Law, 2004). As a whole-parts generalization the relations between the reports, June, the database, and the ethnographer and potentially many other here-nows must be crafted and bundled. By inappropriately emphasizing the magic, read- ers might be alerted to shift their bodies slightly to the side. As in Latour's rendering of the painting's dual message the brownish object invited the audience to lean forward, the inexplicable (and seemingly inappropriately emphasized) magic of the database invites the backgrounding of the modern project of accuracy and accountability through the use of IT. This way the magic database becomes a memento mori directed at the proud ambitions of definitively mapping of the financial money flows in development aid. The database magic disfigures the quests for accuracy and truthful overviews that may work as the 'objective' foundation for policy decisions on how to deliver aid.

How to write an ethnographic story embedding the dual logic of generalizing featuring this episode? How might we arrive at a non-relativizing, non-universalizing description that nevertheless works as a generalization? We have provided one suggestion in which the database figures centrally and come to work as a brownish object/skull. A database might be construed in the narrative that both allows for the making of information exchanges, as well as for the making of unexpected cuts in these exchanges. The story would contrast other stories that feature databases as either cutting the world or handling information 'correctly' albeit with unintended effects. So if we were to follow Holbein/Latour, we would need an object comparable to the brownish object/skull that invites readers to do the work of recognizing the alternative logics of generalizing. We have suggested that the database, which magically cuts the chain of accountability before the eyes of June and the ethnographer, compares to the disfiguring object of the brownish object/skull in Holbein's painting. In highlighting the magic, the database is turned into an object that is both disfiguring and disconcerting. It 
signals that a 'viewer' must 'lean over' in order to see the database as authoritative and as autonomous and capable of making new kinds of knowers (project worker and ethnographer) emerge.

With this analysis we hope to induce ethnographers with a sensibility that allows them to recognize brown and disfiguring objects in their own material. But why would ethnographers of science and technology bother? What sort of analysis is it that carefully crafts a story as an invitation to the reader to shift about so as to constitute a generalization as an irresolvable tension? What precisely is gained in terms of interventionist potential?

As a story about monitoring and chains of accountabilities between donors and recipients of international aid, the incident we have styled here as 'June and the Magic Database' might seem too insignificant to bother about. Nevertheless, the episode is highlighted as extraordinary and worthy of attention by pointing to the database's magic. It shows how such a magic database makes new project workers emerge, as June needs to be equally 'magical' about her own monitoring repertoires in the sense that she thinks up new and surprising standards for communicating with her partners. Such a story features surprising insights about the day-to-day work of handling information technology in small organizations and are of interest to the project workers themselves as well as their manager. Also, they might be of interest to partners in developing countries and intervene in ideas about a smooth and wellfunctioning development bureaucracy.

Equally important, of course, is the way in which the unresolvable tension in the story points to how reflexivity is not simply a matter of being transparent about one's analytical choices. One might ask what the ethnographer sees as she is shifting her position and beginning to focus on the whole-part generalization. She might want to see something else than what was featured in the painting as a Newtonian, linear approach to science. Instead, she might want to see gender. Yet, it is not entirely up to her to decide what she sees as she shifts her position; the brownish object that became a magic database did not allow her the choice of focusing on the gendered aspects of monitoring. This was a specific intervention that could not be made, even if the ethnographer was committed to tell this story. Instead, telling about the database as trusted and autonomous, objective and magical, makes a basis for good faith intervention in academic discussions about aid infrastructures. Good faith here means that the ethnographer faces - not a choice - but a requirement to develop a sense of where exactly to contribute, which makes intervention a matter of writing about how the unavoidable frictions in accountability relations emerge and are handled in the environmental NGO.

\section{Conclusion: The Double Vision and the Partiality is the Intervention}

We have reminded readers of something they have always known, but perhaps have also forgotten when it comes to analytic social sciences: Generalization embeds dual moments. In the social sciences we have learned to pay attention to processes of one-many generalization: The ways spacetime specificities are transformed into general claims. This is the moment Latour calls purification (1993); it embeds abstracting. But social scientists have often failed to recognise the implicit whole-parts generalization - the situating moment that enables the abstracting generalization. We mobilized Latour's reading of Holbein's painting of the ambassadors to distinguish the movement from abstracting one-many generalization to situating whole-part 
generalization that work a number of herenows into the picture. This movement is translation work in Latour's terms. Our view is that we need to recognise and respect both these moments. Doing so enables the double vision that Haraway writes about as a feature of cyborg analysis. It is not enough to artfully claim that we have never been modern. Such a deflating claim does not afford possibilities for intervening.

Part of the interventionist potential of ethnographic stories comes precisely in their capacity to enable double vision. Haraway sees this duality as setting the dizzying Star Wars possibilities of abstraction alongside the particular and situating work of cleaning-up (again and again) those here-now places where those visions are pursued. We have instrumentalised Haraway's exhortation to make this double vision explicit, by suggesting that we need to be sensitive to, and to foreground, ugly brownish interrupting figures in our ethnographic stories. We need to learn to write ethnographic stories that resemble Holbein's ways of painting the ambassadors in the sense that they embed a tension and therefore also a possible comparison between different modes of generalizing.

As has been cogently argued by Holbraad and Pedersen following Strathern, the act of comparing, which is a central aspect of seeking to contain the dual logic in one story, can be considered "a peculiar 'intensification' of the act of fieldwork" (Holbraad \& Pedersen, 2010: 384). This is what Strathern calls the ethnographic moment. It connects with our notion of the ethnographic story in the sense that it also embeds "the capacity to 'transverse' history by cutting away what may at first come across as the most evident connections between one's fieldwork observations and one's object of comparative analysis" (Holbraad \& Pedersen, 2010: 386). Consequently, the brownish object acting as a 'switch' and allowing for the different generalizations to be contained in one story may in fact disappear from this story over the course of time.

In that sense, the ethnographic moment is both more and less than the fieldwork encounter. As a postplural, abstract event, it simultaneously effectuates a 'sharpening' of the anthropologist's field of information (on account of drawing on what is only an insignificant amount of her data), and a 'widening' of the fieldwork material at hand by making its 'less evident' aspects visible. (Holbraad \& Pedersen, 2010: 386)

The interventionist potential of ethnographic stories that are explicit about the double vision through foregrounding within the story a figure that enables switching, is realised through valorising the partiality of our stories. We termed this good faith analysis. Good faith analysis will always be surprising; it will never intervene in any way that was imagined before the study was carried out. For ethnography to be a surprising science, actively engaging the stories' partiality is thus crucial. Partiality is used here in both meanings of Strathern's term: A description is always a part of a whole - which can never be known as a totality; and it is political (biased) - it wants to achieve something in a particular context. In the words of Strathern:

'Partial' captures the nature of the interlocution well, for not only is there no totality, each part also defines a partisan position. Ethnographic truths are similarly partial in being at once incomplete and committed. (Strathern, 2004: 39)

To use Strathern's terms, because of their embedded duality, our stories may acquire 
the capacity to act as "interlocutions". In their partiality they are radically incomplete re-presentations, and simultaneously they take up a position in a politics. Which abstracts and which particulars, which abstracting and situated generalisations this is radically underdetermined. Many directions are possible and many things may follow. Making the next move that is the work that readers must do. They might do nothing and they remain unmoved by the possibilities glimpsed in the double vision. To do nothing is of course to do something as it is to reconstitute current presencing/absencing/othering. Or readers might do something else, inspired by a glimpse of worlds with alternative entities and alternative modes of relating.

Thus, what we add to Latour, Haraway, and Strathern is a modest 'how-to' suggestion. We point to the possibility of identifying figures in ethnographic material that may work as crucial elements in instrumentalizing the insights of such stories on composition, double vision and partiality. The figures should be comparable to the so-called brownish object/skull reminding analysts, readers and informants of the limitation of any generalization and its universalizing tendencies. Similarly, this object figures the ontological commitments of the ethnographer as both located and distributed, and certainly not a matter of choice only. In the field note provided, we see how the magic of the database shakes the ethnographer in her belief that she might actually at some point give back something useful to the people in the environmental NGO, who invited her to interview and shadow them, and who went out of their way to demonstrate the techniques and qualities of their monitoring work. Experiencing the magic of the database makes her remember all the effort and hard work in re-presenting. It thus 'slows down' her work of giving something back to June and her colleagues, which prevents a narrow understanding of what might be 'useful' or 'relevant'. In our view, acknowledging how neither database, project worker, nor ethnographer occupies a fixed position, but can be written in and out of the story in different ways, is generative and thus fruitful for our relationship with multiple stakeholders. We never know precisely what the effects our stories will be, but we do know that bringing them to life as generalizations is infra-ontological as well as epistemological work.

\section{Acknowledgements}

Several colleagues have commented on previous versions of this argument and are sincerely grateful to all of them. In particular, we would like to thank Michael Christie, Casper Bruun Jensen, Alan Irwin, Laura Watts, the anonymous reviewers, and the guest editors of this Science Studies special issue. We are indebted to June and her colleagues in the environmental NGO for their time and support.

\section{References}

Baumann, Z. (1990) Thinking Sociologically (Oxford: Basil Blackwell).

Clifford, J. \& G.E. Marcus (1986) Writing Culture: The Poetics and Politics of Ethnography (Berkeley: University of California Press).

Crapanzano, V. (1992) Hermes' Dilemma and Hamlet's Desire: On the Epistemology of Interpretation (Cambridge, Massachusetts: Harvard University Press).

Daston, L. (1992) 'Objectivity and the Escape From Perspective', Social Studies of Science 22(4): 597-618.

Hacking, I. (1983) Representing and Intervening: Introductory Topics in the Philosophy of Natural Science (Cambridge: Cambridge University Press). 
Haraway, D. (1991) Simians, Cyborgs and Women: The Reinvention of Nature (London: Free Association Books).

Hine, C. (2007) 'Multi-sited Ethnography as a Middle Range Methodology for Contemporary STS', Science, Technology \& Human Values 32(6): 652-71.

Holbraad, M. \& M.A. Pedersen (2009) 'Planet M - The Intense Abstraction of Marilyn Strathern', Anthropological Theory 9(4): 371-94.

Kwa, C. (2002) 'Romantic and Baroque Conceptions of Complex Wholes in the Sciences', in J. Law and A. Mol (eds), Complexities: Social Studies of Knowledge Practices (Duke University Press): 23-52.

Lave, R., P. Mirowski \& S. Randalls (2010) 'Introduction: STS and Neoliberal Science', Social Studies of Science 40: 659-675.

Latour, B. (1993) We Have Never Been Modern (Cambridge, Massachusetts: Harvard University Press).

Latour, B. (2001). "'Thou shall not take the Lord's name in vain" - Being a Sort of Sermon on the Hesitations if Religious Speech $\bigotimes$, Res N79 March $2001 \mathrm{n}^{\circ}$. 39: 215-234.

Latour, B. (2010) 'An Attempt at Writing a 'Compositionist Manifesto', accessed at http://www.bruno-latour.fr/articles on $4 / 102011$

Law, J. (2004) After Method: Mess in Social Science Research (London, New York: Routledge).

Mol, A. (2011) 'One, Two, Three: Cutting, Counting, and Eating', Common Knowledge 17(1): 111-16.

Rouse, J. (1993) 'What are Cultural Studies of Scientific Knowledge?', Configurations 1(1): 1-22.
Stengers, I. (2005) 'The Cosmopolitical Proposal', in B. Latour and P. Weibel (eds), Making Things Public. Atmospheres of Democracy (ZKM centre for Art and Media \& MIT Press, Cambridge MA): 994-1003.

Strathern, M. (2004) Partial Connections (updated edition) (Lanham: Rowman and Littlefield Publishers).

Verran, H. (2001) Science and an African Logic (Chicago: Chicago University Press).

Verran, H. (2007) 'The Telling Challenge of Africa's Economies', African Studies Review 50(2): 163-82.

Verran H. (2010) 'Number as an Inventive Frontier in Knowing and Working Australia's Water Resources', Anthropological Theory 10: 71-78.

Verran, H. (1999) 'Staying True to the Laughter in Nigerian Classrooms', in J. Law and J. Hassard (eds), Actor Network Theory and After (Sociological Review Monographs, Oxford: Blackwell Publishers): 136-55.

Verran, H. (2011) 'The Changes Lives of Measures and Values: From Center Stage in the Fading "Disciplinary" Society to Pervasive Background Instrument in the Emergent "Control” Society', Sociological Review (forthcoming).

Whitehead, A.N (1978) 'Process and Reality: An Essay in Cosmology', corrected edition, D.R. Griffin and D.W. Sherburne (eds) (New York: Free Press).

Winthereik, B.R., A. de Bont \& M. Berg (2002) 'Accessing the World of Doctors and their Computers: Making Available Objects of Study and the Research Site through Ethnographic Engagement', Scandinavian Journal of Information Systems 14(2): 47-58.

Zuiderent-Jerak, T. \& C. Bruun Jensen (2007) 'Editorial Introduction: Unpacking 'Intervention' in Science and Technology Studies', Science as Culture 16(3): 227-35. 


\section{Notes}

1 Note that in claiming generalisation as expressing both one-many and wholeparts forms of reasoning we are making a generalisation about generalising. What enables our generalisation about generalisation is commitment to a whole-parts form of generalising that can contain both one-many and wholeparts forms as parts. These two logics of generalisation have been previously discussed in Verran $(2001 ; 2007 ; 2010)$.

2 The fieldwork that gave rise to this 'note' was carried out in collaboration with Casper Bruun Jensen as part of a project entitled 'Global Chains of Accountability'. It will be published as Monitoring Movements: Infrastructures and Partnership in Development Aid, The MIT Press (Jensen \& Winthereik, forthcoming).
Brit Ross Winthereik

Technologies of Practice Faculty Group, IT University of Copenhagen

Rued Langgaards Vej 7, 2300 Copenhagen S, Denmark

brwi@itu.dk

Helen Verran

School of Historical and Philosophical Studies, University of Melbourne

Victoria, Australia, 3010.

The Northern Institute, Charles Darwin University

Darwin NT 0909, Australia

hrv@unimelb.edu.au 